\title{
Occurrence of intimal thickening of the peripheral arteries in response to local vibration
}

\author{
A OKADA, R INABA, T FURUNO
}

From the Department of Public Health, School of Medicine, Kanazawa University, Kanazawa, 920 Japan

ABSTRACT Experiments were performed to elucidate a possible mechanism for the peripheral circ $\overrightarrow{g^{2}}$ latory disturbance caused by vibration. Rats were exposed to local vibration $(60 \mathrm{~Hz}, 5 \mathrm{G})$ on thegr hind legs for four hours a day for 30 days or 90 days. With exposure for 30 days the small arteries at the exposed site did not change. With exposure for 90 days, however, disruption of the internat elastic lamina was observed in the small arteries. This disruption was followed by focal cell pró liferation with regenerative formation of collagen and elastic fibres. The fibrocellular thickening of the intima was further augmented, and in addition a complete stenosis of the lumen of the small arteries was observed. Electron micrography showed that the fibrocellular thickening of the intima consisted of a proliferation of arterial smooth muscle cells and numerous collagen and elastic fibres. These alterations were not observed in the arteries of the controls. The thickness of the media dif not differ between the control and exposed groups or in animals with different durations gf exposure. Concerning plasma total cholesterol, HDL-cholesterol, and lipoperoxide, there were no8 significant differences between the control and exposed groups after either 30 or 90 days, but the whole blood viscosity was significantly increased by day 90 . This finding may be related to the intimal thickening.

To clarify the mechanism of the occurrence of Raynaud's phenomenon, which is a characteristic symptom of the vibration syndrome, it is important to study the effects of hand arm transmitted vibration. Some researchers have reported histological changes in the peripheral arteries in workers with Raynauds phenomenon using vibrating tools. ${ }^{12}$ It is necessary, however, to ascertain experimentally whether or not these changes are specific to exposure to local vibration.

Recently, we have succeeded in demonstrating the occurrence of intimal thickening in the peripheral arteries of the rat after long term exposure to local vibration. The purpose of the present study was to evaluate the relation between the histological changes in the peripheral arteries and the mechanism of the occurrence of Raynaud's phenomenon in response to vibration.

\section{Materials and methods}

MATERIALS

Twenty male Wistar rats, initially weighing $230-250 \mathrm{~g}$, were used in groups of five.

Accepted 27 August 1986
EXPOSURE TO VIBRATION

The apparatus used to induce vibration comprised electromagnetic shaker (EMIC 513-A) with a shakinf power of $7.5 \mathrm{~kg}$ (vibration frequency range $5-5000 \mathrm{~Hz}$ ) coupled to an amplifier (TACHIKAW TA-100), a function oscillator (TORIO AG202), and a vibration meter (EMIC 505-D).

The animals were placed prone in individual mest cages. The hind legs were outside the cage and the plantar surfaces were horizontally fixed to the vibrating plate by means of double sided adhesic tape, so that the vibration would be transmitted only to the hind legs. The part of the cage containing the rest of the animal was fixed on a non-vibrating plat separated from the shaker. The hind legs of the rat: were exposed to vertical sinusoidal vibration with of frequency of $60 \mathrm{~Hz}$ under a constant acceleration of $5 \mathrm{G}$. The duration of exposure was for four hours day for either 30 or 90 days.

Before the experiments, the rats were trained fe्f one week to ride on the vibrating platform.

The control animals for each experiments were als placed in wire mesh cages, which were placed near to the electromagnetic shaker during the exposune experiment so that any noise produced would experienced but not the vibration.

The temperature in the laboratory room wo 
maintained at $20 \pm 2^{\circ} \mathrm{C}$ and a 12 hour "light-dark" cycle was maintained in the animal room. Food and water were provided freely before the start of the experiment.

\section{PATHOHISTOLOGICAL OBSERVATION}

Eighteen hours after the last exposure, samples for electron microscopic examination were obtained from the dorsal site of the foot. Samples for electron microscopic examination were fixed with $2.5 \%$ glutaraldehyde for one hour, and postfixed in $2 \%$ osmium tetroxide for one hour, both of which were buffered with $0 \cdot 1 \mathrm{M}$ sodium cacodylate at $\mathrm{pH} 7 \cdot 4$. After dehydration, the samples were embedded in Epon 812 filled gelatin capsules. Thin sections were made with an LKB Ultrotome and were stained with uranyl acetate and lead citrate. Samples were examined with a Hitachi H-500 electron microscope operating at $75 \mathrm{kV}$.

For microscopic examination, cross sections of the foot, $1.5 \mathrm{~cm}$ peripheral from the ankle, were obtained and were stained with haematoxylin-eosin and elastica-Van Gieson. According to Suwa's histometrical method, cross sections of the arteries were reduced to the state in which the intimal elastic lamina was perfectly stretched and the thickness of the media (D) and the radius (R) were measured and the ratio $R / D$ calculated. ${ }^{3}$

\section{BLOOD COLLECTION}

Immediately after the samples had been taken for electron microscopic examination, blood was collected into heparinised tubes after decapitation. The blood was used for measuring the whole blood viscosity and plasma lipid components (total cholesterol, HDL-cholesterol, and lipoperoxide).

\section{MEASUREMENT OF WHOLE BLOOD VISCOSITY}

AND PLASMA LIPIDS

Whole blood viscosity was measured with a WellsBrookfield cone plate microviscometer (model LVT) at $37^{\circ} \mathrm{C}$ at two shear rates, 230 and $115 \mathrm{~s}^{-1}$.

The plasma concentrations of total cholesterol (TCH) and HDL-cholesterol (HDL-C) were measured by enzymatic methods; plasma concentrations of lipoperoxide (LPO) were determined using the fluorometric method developed by Yagi. ${ }^{4}$

STATISTICAL ANALYSIS

The statistical significance of the results was tested with Student's $t$ test.

\section{Results}

EFFECTS OF LOCAL VIBRATION EXPOSURE ON THE INTIMA OF THE ARTERIES

After 30 days exposure, the small arteries at the exposed site did not change histologically. In three of the five rats exposed for $\mathbf{9 0}$ days, however, there were some histological changes in the small arteries at the exposed site; alterations in the arteries of the control group were not observed. Figure 1 shows the histological changes in the small artery of the rat's hind leg after exposure to local vibration for 90 days; disruption of the internal elastic lamina may be observed in the artery. This disruption was followed by focal cell proliferation with regenerative formation of collagen and elastic fibres. Figure 2 shows a fresh fibrin thrombus in the lumen of the small artery observed at the exposed site in one of the five rats exposed for 90 days and in figure 3 mild fibrocellular thickening of the intima may be seen. Further thickening of the intima was followed by complete stenosis of the lumen observed (figure 4). Figure 5 shows that the fibrocellular thickening of the intima results from the proliferation of arterial smooth muscle cells from the media associated with the formation of collagen and elastic fibres.

EFFECTS OF LOCAL VIBRATION EXPOSURE ON THE MEDIA OF THE ARTERIES

Figure 6 shows the changes in medial thickness of the arteries as represented by the ratio $D / R$. We found that $D / R$ in the arteries of the rat changed abruptly when the radius was approximately $35 \mu$. Thus we separated the results depending on whether it was greater or less than $35 \mu$ but the medial thickness showed no significant differences between the control and the exposed groups with either $\mathbf{3 0}$ or $\mathbf{9 0}$ days exposure.

\section{EFFECTS OF LOCAL VIBRATION EXPOSURE ON} WHOLE BLOOD VISCOSITY AND PLASMALIPIDS Figure 7 shows the effects of vibration on the whole blood viscosity measured at shear rates of 115 and $230 \mathrm{~s}^{-1}$. There were no significant differences between the control and the exposed group at 30 days exposure. With 90 days exposure, however, the exposed group showed a significantly higher blood viscosity at each shear rate compared with the controls $(\mathrm{p}<0.05)$. There were no significant differences in plasma concentrations of TCH, HDL-C, or LPO between the controls and the exposed groups at either duration of exposure (table).

\section{Discussion}

Both Pellegrini and Richard have suggested the possibility that there is some relation between organic changes in the artery and the occurrence of Raynaud's phenomenon after exposure to vibration. ${ }^{56}$ In the present study we found that intimal thickening of the small arteries in the rat was induced by repetitive 


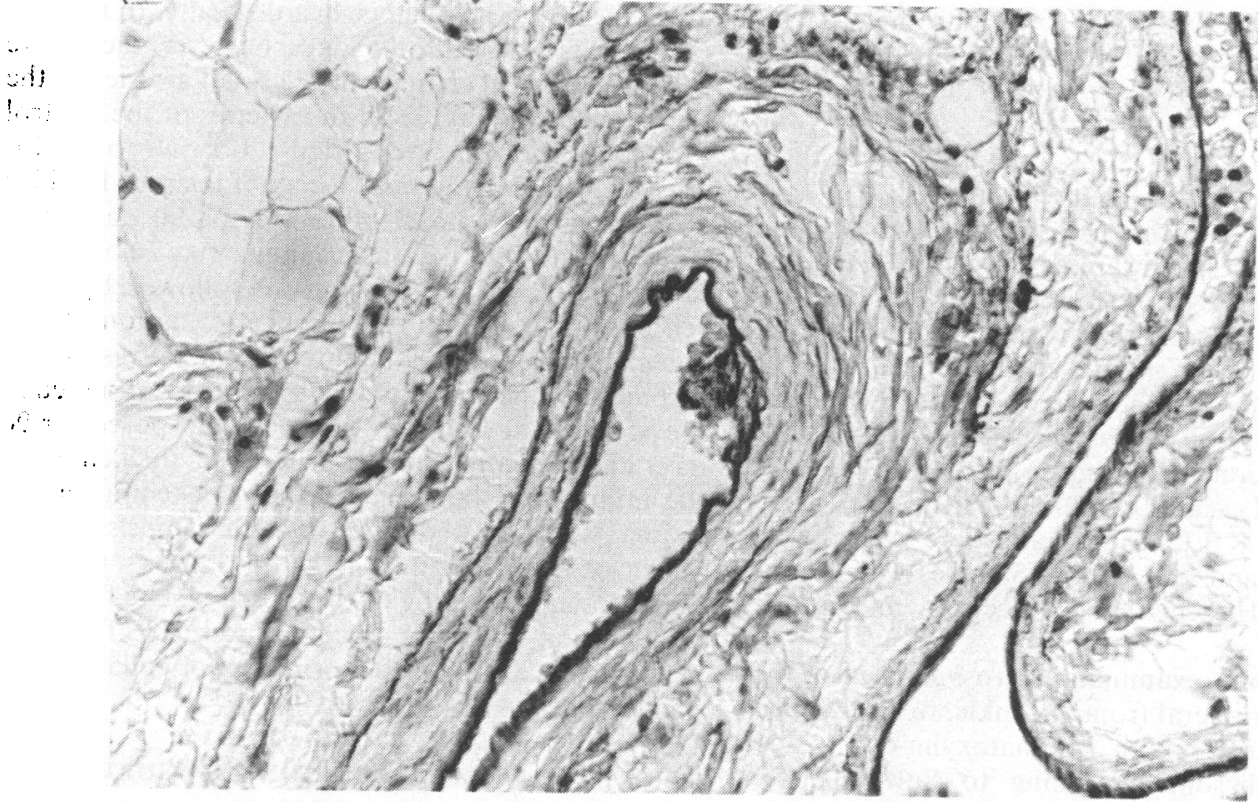

Fig 1 Small artery of rat hind leg after exposure to local vibration for four hours a day for 90 days. Disruption of internal elastic lamina and focal cell proliferation with formation of collagen and elastic fibres are shown. (Elastica-Van Gieson stain, $\times 330$.)

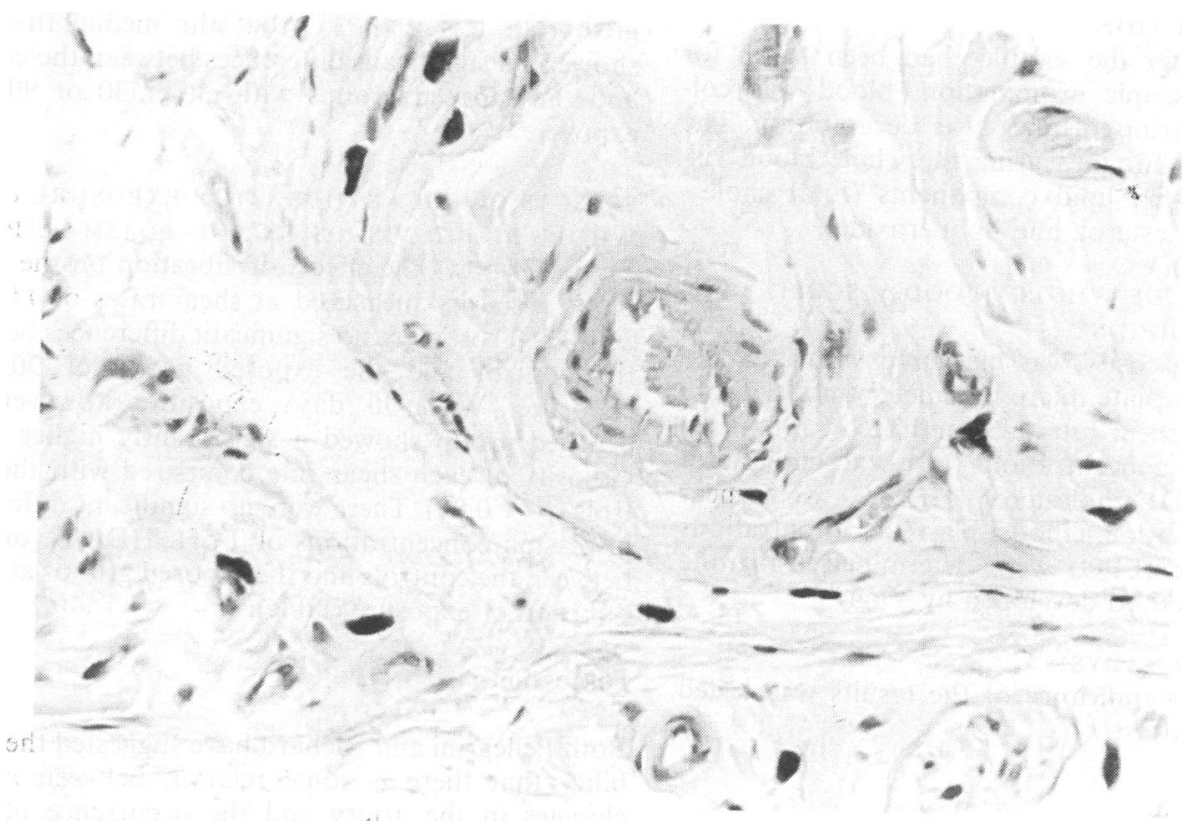

Fig 2 Small artery of rat hind leg after exposure to local vibration for four hours a day for 90 days. A fresh fibrin thrombus is shown in lumen of small artery. (Haematoxylin-eosin stain,
$\times 330$.) 


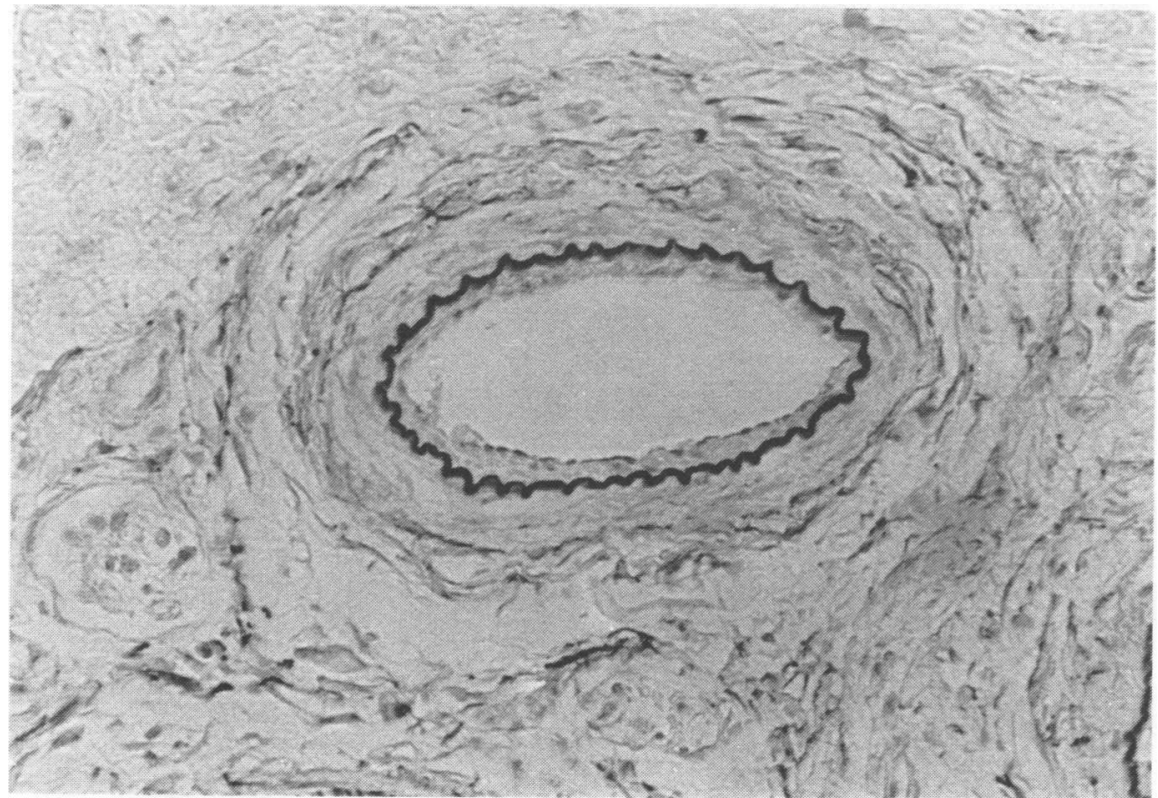

Fig 3 Small artery in rat hind leg after exposure to local vibration for four hours a day for 90 days. Mild fibrocellular thickening of intima is shown. (Elastica-Van Gieson stain, $\times 330$.)

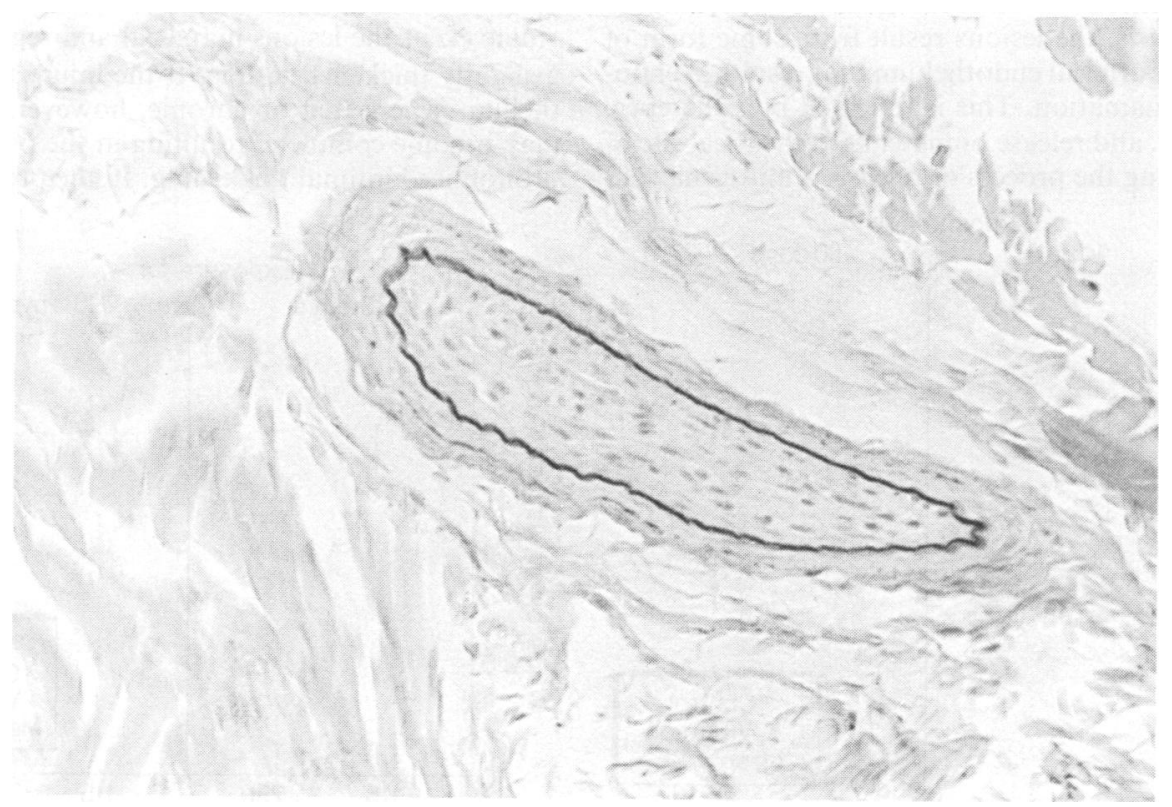

Fig 4 Small artery in rat hind leg after exposure to local vibration for four hours a day for 90 days. Severe intimal thickening and complete stenosis of lumen are shown. (Elastica-Van Gieson stain, $\times 330$.) 


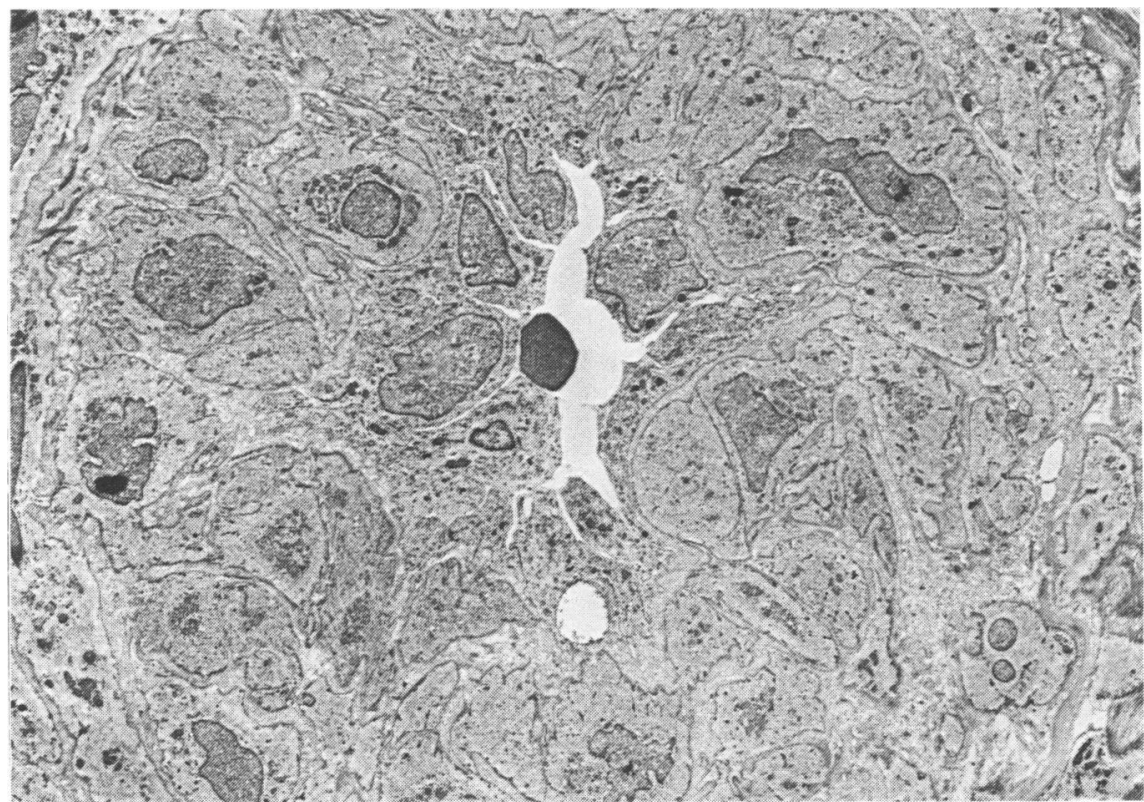

Fig 5 Electron micrograph of small artery of rat hind leg after exposure to local vibration for four hours a day for 90 days. Proliferation of arterial smooth muscle cells from media associated with formation of collagen and elastic fibres is shown $(\times 4500)$.

and long term exposure to local vibration (figs 1-5). Recently, Ross et al proposed a new hypothesis for the pathogenesis of atherosclerosis. ${ }^{7}$ According to this hypothesis, the lesions result from some form of injury to the arterial endothelium that results in endothelial desquamation. This is followed by adherence, aggregation, and release of platelets at the focal site of injury. During the process of release, a mitogenic fac-

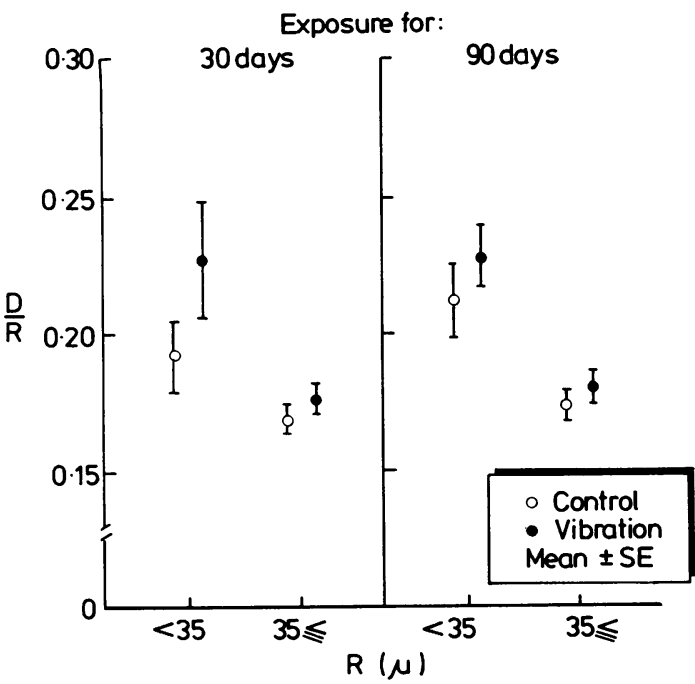

Fig 6 Changes in medial thickness (represented as $D / R$ ) of arteries caused by local vibration. tor is secreted from the platelets which gains entry into the arterial wall, resulting in focal intimal prolis eration of the smooth muscle cells. If the injury is single event the lesions may heal and regress, leavirit a slightly thickened intima. If the injury to the end@ thelium is repeated or chronic, however, the lesions may become complete, resulting in the production of pronounced intimal thickening. In the present experi-

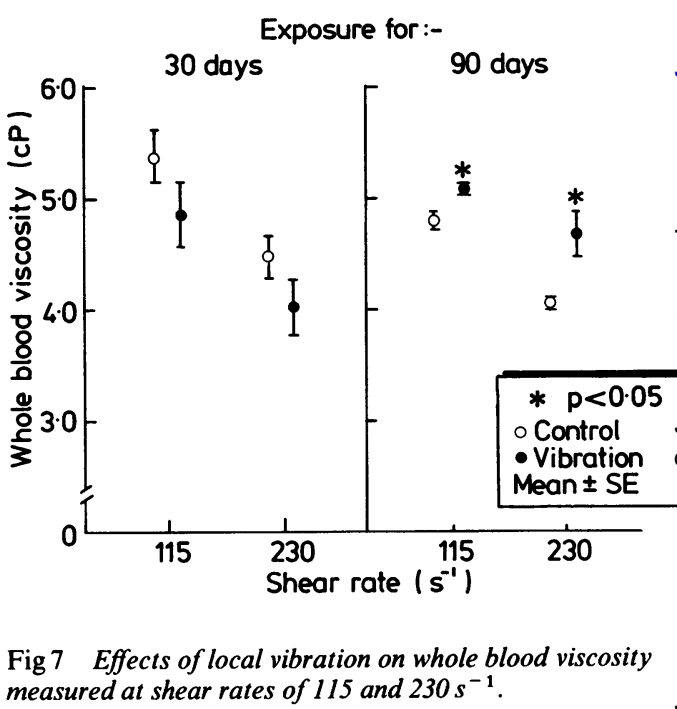
measured at shear rates of 115 and $230 \mathrm{~s}^{-1}$. 


\begin{tabular}{|c|c|c|c|c|}
\hline & & $\begin{array}{l}\text { Total cholesterol } \\
(\mathrm{mg} / \mathrm{dl})\end{array}$ & $\begin{array}{l}\text { HDL-cholesterol } \\
(\mathrm{mg} / \mathrm{dl})\end{array}$ & $\begin{array}{l}\text { Lipoperoxide } \\
(\mathrm{nmol} / \mathrm{ml})\end{array}$ \\
\hline Exposure for 30 days & $\begin{array}{l}\text { Control } \\
\text { Vibration exposed }\end{array}$ & $\begin{array}{l}66 \cdot 3 \pm 3 \cdot 4 \\
69 \cdot 2 \pm 3 \cdot 1\end{array}$ & $\begin{array}{l}22 \cdot 3 \pm 0.9 \\
23.0 \pm 1 \cdot 0\end{array}$ & $\begin{array}{l}3.65 \pm 0.21 \\
3.46 \pm 0.29\end{array}$ \\
\hline Exposure for 90 days & $\begin{array}{l}\text { Control } \\
\text { Vibration exposed }\end{array}$ & $\begin{array}{l}47 \cdot 0 \pm 2 \cdot 5 \\
45 \cdot 4 \pm 2 \cdot 9\end{array}$ & $\begin{array}{l}19 \cdot 8 \pm 1.8 \\
19.0 \pm 1.6\end{array}$ & $\begin{array}{l}2.42 \pm 0.15 \\
2.78 \pm 0.38\end{array}$ \\
\hline
\end{tabular}

Each value represents the mean $\pm \mathrm{SE}$.

ment a fresh fibrin thrombus was observed in the small artery after 90 days exposure (fig 2 ). Therefore, it is considered that vibration induces intimal thickening through the processes described by Ross. ${ }^{7}$

Azuma et al reported that, after vibratory stimulation, the responsiveness of arterial smooth muscle to noradrenaline was greatly increased and that the vasoconstrictive activity of noradrenaline was also greatly raised. ${ }^{8}$ Kobori observed that endothelial injury may be caused to the mesenteric artery by the injection of methoxamine $\mathrm{HCl}$, which is a vasoconstrictive agent. ${ }^{9}$ Therefore it is considered that the sensitivity of arterial vessels to noradrenaline increases after exposure to vibration and that the artery constricts or goes into spasm, thus causing injury to the endothelium. Moreover, it may be supposed that if repeated or chronic endothelial injury was caused by local vibration, pronounced intimal thickening of the artery would appear at the exposed site. In the present experiment histological changes were observed in the small arteries at the exposed site after 90 days exposure but not after 30 days. This also suggests that repetitive injury to the endothelium is important in producing severe intimal thickening.

Ashe and Williams reported that the clinical condition of workers using vibrating tools whose skin biopsy showed intimal thickening of the artery was more severe than those without. ${ }^{1}$ The data from the present study suggested that there is some relation between the intimal thickening in the small arteries and the attacks of Raynaud's phenomenon. Our results support the theory that intimal thickening is related to the severity of the attack.

In general, vibration induced medial thickening of the artery is given greater attention than intimal thickening. ${ }^{2}$ Therefore we examined whether vibration can induce changes in the thickness of the media of the artery but found this was not the case. Furuyama reported significant correlations between the medial thickness of the mesenteric and femoral arteries and the systemic blood pressure. ${ }^{3}$ Therefore, the results of skin biopsy of workers using vibrating tools should be interpreted with due consideration to their blood pressure.

Changes in blood lipids induced by local vibration were not observed in this experiment; plasma $\mathrm{TCH}$, HDL-C, and LPO concentrations which are consid- ered to be related to atherosclerosis ${ }^{10}$ were not significantly different between the control and the exposed groups for any duration of exposure. Nevertheless, the whole blood viscosity was significantly increased after 90 days exposure and not 30 days. Fujinaga reported that in workers with Raynaud's phenomenon using vibrating tools the whole body viscosity was significantly higher than in normal workers. Therefore, there may be some relation between the increase in whole blood viscosity and the intimal thickening seen in the small arteries at the exposed site and, in addition, whole blood viscosity may be useful in diagnosing the hand-arm vibration syndrome.

We are grateful to Dr S Katsuda and Dr Y Oda (department of pathology, School of Medicine, Kanazawa University) for their valuable advice. We also thank Mr T Yamaguchi for his technical help.

\section{References}

1 Ashe WF, Williams N. Occupational Raynauds II. Arch Environ Health. 1964;9:425-33.

2 Takeuchi T, Imanishi H. Histopathologic observations in finger biopsy from thirty patients with Raynaud's phenomenon of occupational origin. Journal of the Kumamoto Medical Society 1984;58:56-70.

3 Furuyama M. Histochemical investigations of arteries in reference to arterial hypertension. Tohoku J Exp Med 1962;76: 388-414.

4 Yagi K. A simple fluorometric assay for lipoperoxide in blood plasma. Biochem Med 1976;15:212-6.

5 Pellegrini P. A study of the anatomical substrate of occupational microangiography caused by vibrating instruments. Med Lav 1968;59:180-208.

6 Richard RL. Raynaud's syndrome. The Hand 1972;4:95-9.

7 Ross R, Glomset J, Harker L. Response to injury and atherogenesis. Am J Pathol 1977;86:675-84.

8 Azuma T, Ohhashi T, Sakaguchi M. An approach to the pathogenesis of "white finger" induced by vibratory stimulation: acute but sustained changes in vascular responsiveness of canine hind limb to noradrenaline. Cardiovasc Res 1980;14: 725-30.

9 Kobori K. Pathomorphological study on experimental arterial contraction (spasm) in rats. Journal of the Japanese College and Angiology 1976;16:613-26.

10 Yagi K, Ohkawa H, Ohishi N, Yamashita M, Nakashima T Lesion of aortic intima caused by intravenous administration of linoleic acid hydroperoxide. J Appl Biochem 1976;3:58-65.

11 Fujinaga $\mathrm{H}$. Epidemiologic findings on blood viscosity. Nippon Eiseigaku Zasshi 1984;39:717-28. 